\title{
Awareness and use of family planning methods among women in Northern Saudi Arabia
}

\author{
Ghzl Ghazi Alenezi ${ }^{1}$ and Hassan Kasim Haridi ${ }^{2 *}$ (D
}

\begin{abstract}
Background: Evaluation of awareness and use of family planning methods is important to improve services and policies. This study aimed to assess awareness and use of family planning methods among women in an urban community in the north of Saudi Arabia.

A cross-sectional study was carried out in a maternity hospital and 12 primary health care (PHC) centers in Hail City between December 1st, 2019, and May 30, 2020.

Results: Four hundred married sexually active women aged 18-49 years were interviewed using a pretested structured questionnaire. The mean age of the participant was $32.0 \pm 7.5$ years, $73.5 \%$ were university educated, and $58 \%$ were housewives. More than two-thirds of them (67.6\%) had $\geq 3$ living children. Most women (85\%) ever used, and $66.5 \%$ were currently using any method of contraception; however, only one in five who get counseling for the contraceptive method used, and $40 \%$ of the last births were unplanned for. Almost all women reported unavailable family planning clinics in their primary healthcare centers. Most participants (83.0\%) desired to have $>3$ children, which indicates that the main purpose of family planning was child spacing rather than limitation. Relying on natural methods as being safer (36.3\%), desire to have more children (19\%), being afraid from side effects (15.3\%), and possibility of difficulty getting pregnant or might cause infertility (13.0\%) were reasons the participants viewed for unsung modern contraceptives.

Conclusion: This study revealed that most women in urban Hail community, northern Saudi Arabia, were aware about and have a positive attitude towards family planning. The majority of the participants ever used, and twothirds were currently using any contraceptive method/s, which is higher than the national estimate for Saudi Arabia. However, only one in five counseled by healthcare providers for the type of contraceptive method used. Unavailability of family planning services in primary health care centers impedes getting professional counseling. It is imperious to consider family planning clinics to provide quality family planning services.
\end{abstract}

Keywords: Awareness, Contraceptives, Family planning, Practice, Saudi Arabia

\footnotetext{
* Correspondence: hassankasim@hotmail.com

${ }^{2}$ Academic Affairs \& Postgraduate Studies, General Directorate of Health Affairs, Najran, Saudi Arabia
}

Full list of author information is available at the end of the article

\section{Springer Open}

(c) The Author(s). 2021 Open Access This article is licensed under a Creative Commons Attribution 4.0 International License, which permits use, sharing, adaptation, distribution and reproduction in any medium or format, as long as you give appropriate credit to the original author(s) and the source, provide a link to the Creative Commons licence, and indicate if changes were made. The images or other third party material in this article are included in the article's Creative Commons licence, unless indicated otherwise in a credit line to the material. If material is not included in the article's Creative Commons licence and your intended use is not permitted by statutory regulation or exceeds the permitted use, you will need to obtain permission directly from the copyright holder. To view a copy of this licence, visit http://creativecommons.org/licenses/by/4.0/. 


\section{Background}

A woman's ability to choose whether and when to become pregnant directly affects her health and wellbeing. Voluntary family planning saves lives and accelerates sustainable human and economic development [1]. Family planning implies the ability of individuals and couples to anticipate and attain their desired number of children and the spacing and timing of their births [2]. Use of contraception prevents pregnancy-related health risks for women and children. When births are separated by less than 2 years, the infant mortality rate is $45 \%$ higher than it is when births are 2-3 years and 60\% higher than it is when births are four or more years apart [3]. Family planning offers a range of potential nonhealth benefits that encompass expanded educational opportunities and empowerment for women and sustainable population growth and economic development for countries [4]. Family planning is achieved through contraception, defined as any means capable of preventing pregnancy, and through the treatment of involuntary infertility. The contraceptive effect can be obtained through temporary or permanent means. Temporary methods include periodic abstinence during the fertile period, coitus interrupts (withdrawal), using the naturally occurring periods of infertility (e.g., during breastfeeding and postpartum amenorrhea), through the use of reproductive hormones (e.g., oral pills and long-acting injections and implants), placement of a device in the uterus (e.g. ,copper-bearing and hormone-releasing intrauterine devices), and interposing a barrier that prevents the ascension of the sperm into the upper female genital tract (e.g., condoms, diaphragms, and spermicides). Permanent methods of contraception include male and female sterilization [2, 4].

Availability of family planning methods and family planning service quality are important dimensions of the global health policies [5]. Regarding availability, the principles state that health care facilities, providers, and contraceptive methods need to be available "to ensure that individuals can exercise full choice from a full range of methods" and that furthermore, contraceptive methods are to be accessible without informational or other barriers. Regarding service quality issues, the principles state that "client-provider interactions respect informed choice, privacy and confidentiality, client preferences, and needs" [5].

Even though women in Saudi Arabia have a high total fertility rate compared to developed countries, a major change has occurred in the last decades. The total fertility rate decreased from 7.17 in 1980 to 4.10 in 2000 and to 2.27 in 2020 [6], a decrease by $45 \%$ in the last two decades and by more than two thirds in the last four decades. This substantial change in fertility profile occurred as a consequence of sociodemographic development in the Saudi community, especially in women's education and work $[7,8]$ as important factors in changing the beliefs of fertility and behaviors towards birth spacing, and the use of the contraceptives.

Monitoring and evaluation of awareness and utilization of family planning methods in communities are important to improve the quality and effectiveness of services, policies, and planning with resulting beneficial impacts on health and quality of life of women, children, families, and communities. An important aspect of research in this respect is to explore views and practices of women in the reproductive age with regard to family planning and fertility preferences, so we aimed in this study to assess awareness, attitude, and use of family planning methods among women in urban community at the north of Saudi Arabia.

\section{Methods \\ Study design and the participants}

This cross-sectional study was conducted in Hail City, the main urban area in Hail region, at the north of Saudi Arabia, between December 1st, 2019, and May 30, 2020. A maternity hospital and 12 primary health care (PHC) centers were the setting of this study. PHC centers were selected at random among a total of 24 PHC centers serving all neighborhood of Hail City. The eligible subjects were married women, residing in Hail City for at least 1 year, aged 18-49 years, who were sexually active, not in the menopause with no contraindication from getting pregnant. Participants were selected at random from women in the waiting areas, who visited the selected health care facility for any reason and invited to undergo an interview. Sample size was calculated using Cochran's Sample Size Formula [9] to comprise 384 participants, assuming $50 \%$ of women are using contraceptive methods (to maximize sample size) and 5\% margin error within 95\% confidence level. However, a successful 400 eligible participants were interviewed. A prior consent was obtained from the participants before the interview. Efforts were maximally taken during recruiting and interviewing eligible participants in the study to avoid any potential selection or information bias.

\section{Data collection and analysis}

A pretested, predesigned questionnaire was used by the investigator to interview the selected study participants. The questionnaire included sociodemographic information regarding age, education, family size, and family income, and questions covered awareness with regard to the concept and methods of family planning and attitude towards and practice of family planning. Data obtained was coded, entered into, and analyzed using Epi Info 
7.1.3 program (CDC, Atlanta, GA, USA). Descriptive statistical measures as percentages and proportions were used to express qualitative data. Quantitative data were expressed as mean and standard deviation. Data was presented as tables and graphs as relevant.

\section{Result}

A total of 400 women completed the interview among 418 women asked to participate in the study (96.7\% response rate). Time factor and wouldn't like to share personal information were most of the reasons mentioned for non-participation.

The mean age of the participants was $32.0 \pm 7.5$ years. The age-wise distribution of the participants is shown in Table 1. Most participants received university education $(294,73.5 \%)$. More than half $(211,52.8 \%)$ of the participants reported family income $<10,000$ SR, while those who reported high income $\geq 15,000$ SR were 96 (24.0\%). The mean living children per woman was $2.9 \pm 2.5$ children, with about one-third $(130,32.5 \%)$ had more than 3 children (Table 1).

Table 1 Sociodemographic characteristics of respondents

\begin{tabular}{|c|c|c|}
\hline Variable & Frequency $(n=400)$ & Percent \\
\hline \multicolumn{3}{|l|}{ Age group in years } \\
\hline$<25$ & 55 & 13.8 \\
\hline $25-29$ & 128 & 32.0 \\
\hline $30-39$ & 142 & 35.5 \\
\hline $40+$ & 75 & 18.8 \\
\hline Mean age in years $\pm S D$ & $32.0 \pm 7.50$ & \\
\hline \multicolumn{3}{|c|}{ Level of education of respondent } \\
\hline No formal education & 11 & 2.8 \\
\hline Primary/middle school & 36 & 9.0 \\
\hline High school & 59 & 14.8 \\
\hline University/higher & 294 & 73.5 \\
\hline \multicolumn{3}{|c|}{ Employment status of respondent } \\
\hline Housewife & 232 & 58.0 \\
\hline Working & 122 & 30.5 \\
\hline Student & 46 & 11.5 \\
\hline \multicolumn{3}{|l|}{ Family income (SR) } \\
\hline$<5000$ & 42 & 10.5 \\
\hline 5000-9999 & 169 & 42.3 \\
\hline $10,000-14,900$ & 93 & 23.3 \\
\hline$\geq 15,000$ & 96 & 24.0 \\
\hline \multicolumn{3}{|l|}{ No. of living children } \\
\hline $0-1$ & 135 & 33.8 \\
\hline $2-3$ & 135 & 33.8 \\
\hline$\geq 4$ & 130 & 32.5 \\
\hline Mean \pm SD & $2.9 \pm 2.52$ & \\
\hline
\end{tabular}

Table 2 summarizes awareness about and attitude towards family planning among the study participants. About two-thirds 259 (64.8\%) perceived family planning concept as a means for pregnancy spacing, while 88 $(22.0 \%)$ perceived it as a means of pregnancy limitation, the others $53(13.3 \%)$ were not familiar with the meaning of family planning. Almost all participants (399; 99.8\%) were familiar with hormonal contraceptive pills, IUDs (387, 96.8\%), and withdrawal (396, 99.0\%), and most $(364,91.0 \%)$ were familiar with condom and breastfeeding $(330,82.5 \%)$ as a means of contraception methods. Still, a good percent was familiar with abstinence $(307,76.8 \%)$ and injectable hormonal $(252,63.0 \%)$ and hormonal patch $(245,61.3 \%)$ contraceptives. Less commonly familiar methods were female sterilization (145, 36.3\%), female barrier (92, 23.0\%), and male sterilization $(68,17.0 \%)$. Figure 1 demonstrates sources of knowledge about family planning among participants. Most sources were non-reliable sources, such as family/ friends $(67.5 \%)$, general internet sites $(43.8 \%)$, and social media (34/0\%); meanwhile, only half $(50.3 \%)$ of the participants reported consulting healthcare workers.

The vast majority $(384,96.0 \%)$ were favoring family planning (agree/strongly agree), with almost the same percent mentioned that family planning have multiple benefits. More than two-thirds $(282,70.5 \%)$ of the participating women reported husbands' support with regard to family planning. A small percent $(17.0 \%)$ desired a small number (1-3) of children; $55.0 \%$ desired more than 3 children, while $28.0 \%$ would not like to limit their children number and leave it open. More than twothirds (67.5\%) preferred pregnancy spacing for more than 2 years.

Table 3 summarizes family planning practices as reported by participant women. The majority $(n=341$; 85.3\%, CI $=81.4-88.6)$ ever used and 266 (66.5\%, CI= 61.6-71.1) were currently using contraceptive method/s. Methods currently mostly used were pills $(n=144$, $54.1 \%)$, withdrawal $(n=58,21.8 \%)$, IUDs $(n=29,10.9 \%)$, hormonal patches $(n=14,5.3 \%)$, and condom $(n=12$, 4.5\%) (Fig. 2).

Less than half $(n=144 ; 44.0 \%)$ of the respondents reported that their husbands practice contraception. The frequently used method was withdrawal $(n=147,36.8 \%)$ and to a lesser extent condom $(n=55,13.8 \%)$ and abstinence during ovulation period $(n=32,8.0 \%)$.

More than $60 \%(121,60.5 \%)$ bought the contraceptive directly from private pharmacies over the counter as a personal choice, others $(52,26.0 \%)$ brought the contraceptive method after medical advice in private dispensary/hospital, and few $(27,13.5 \%)$ were prescribed after medical advice in a governmental health care facility.

Table 4 summarizes respondent's views about the important reasons behind the non-use of modern 
Table 2 Awareness about and attitude towards family planning

$n$

\section{Perceived purpose of family planning}

A mean of pregnancy spacing

A mean of pregnancy limitation

Not familiar

Awareness regarding various methods of family planning

\section{Modern methods}

Pills

Injectable hormonal

Hormonal patches

Hormonal implants

IUDS

Condom

Female barrier

Female sterilization

Male sterilization

Traditional methods

Withdrawal

Breastfeeding

Abstinence

259

ttitude towards family planning

Favoring family planning (agree/strongly agree)

Family planning have good benefits (agree/strongly agree)

My husband is supporting me for family planning (agree/strongly agree)

Still I want more children (yes)

Preferred number of children

$$
1-3
$$

No preference

Preferred child spacing (years)

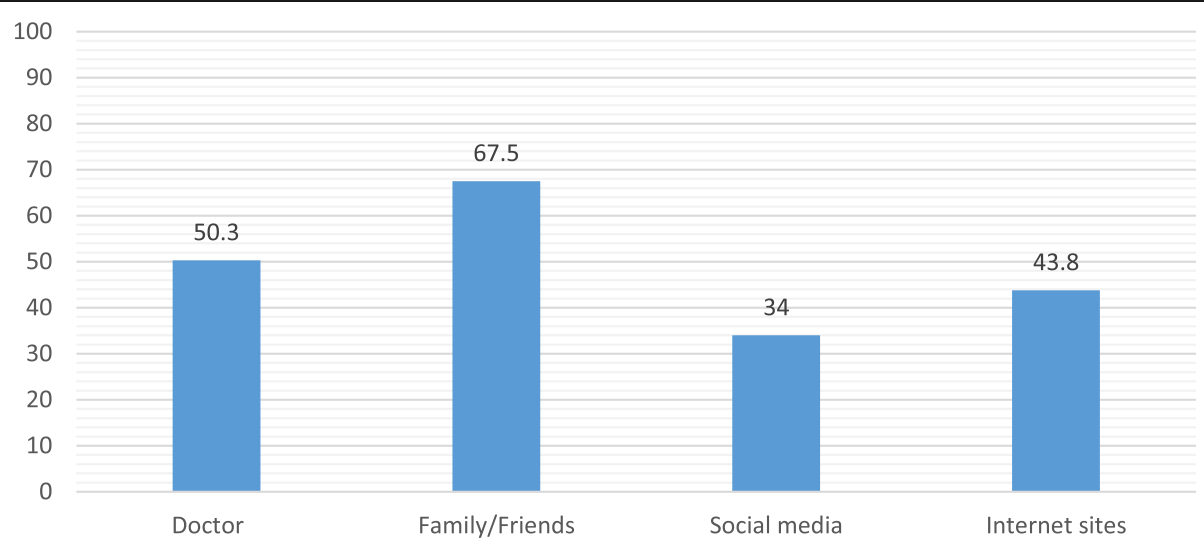

Fig. 1 Sources of knowledge about family planning methods (\%) 
Table 3 Family planning practice

\begin{tabular}{|c|c|c|}
\hline Variables & $n$ & $\%$ \\
\hline \multicolumn{3}{|l|}{ Ever used contraceptive method } \\
\hline Yes & 341 & $85.3^{\mathrm{a}}$ \\
\hline No & 59 & 14.7 \\
\hline \multicolumn{3}{|l|}{ Currently use contraceptive method } \\
\hline Yes & 266 & $66.5^{\mathrm{b}}$ \\
\hline No & 85 & 21.3 \\
\hline Being pregnant & 49 & 12.3 \\
\hline \multicolumn{3}{|l|}{ Type of the contraceptive method currently used } \\
\hline Pills & 144 & 54.1 \\
\hline Withdrawal & 58 & 21.8 \\
\hline IUD & 29 & 10.9 \\
\hline Hormonal patches & 14 & 5.3 \\
\hline Condom & 12 & 4.5 \\
\hline Other methods & 9 & 3.4 \\
\hline \multicolumn{3}{|l|}{ Husband practices contraceptive method } \\
\hline Yes & 176 & 44.0 \\
\hline No & 224 & 56.0 \\
\hline \multicolumn{3}{|l|}{ Husband contraceptive method used } \\
\hline Condom & 55 & 13.8 \\
\hline Withdrawal method & 147 & 36.8 \\
\hline Abstinence during ovulation period & 32 & 8.0 \\
\hline \multicolumn{3}{|l|}{ Source of the contraceptive method prescribing } \\
\hline Governmental hospital & 27 & 13.5 \\
\hline Private Dispensary/Hospital & 52 & 26.0 \\
\hline Directly from a pharmacy & 121 & 60.5 \\
\hline \multicolumn{3}{|c|}{ Who advised the type of the contraceptive method } \\
\hline Doctor/nurse & 46 & 21.8 \\
\hline Family/friends & 49 & 23.2 \\
\hline Personal choice based on general information & 116 & 55.0 \\
\hline \multicolumn{3}{|l|}{$\begin{array}{l}\text { Duration of use of the last contraceptive method } \\
\text { (years) }\end{array}$} \\
\hline$<1$ year & 54 & 14.9 \\
\hline $1-<2$ & 64 & 17.6 \\
\hline $2-3$ & 51 & 14.0 \\
\hline$>3$ & 42 & 11.6 \\
\hline Not used & 152 & 41.9 \\
\hline \multicolumn{3}{|l|}{ Was the last child planned for? } \\
\hline Yes & 240 & 60.0 \\
\hline No & 160 & 40.0 \\
\hline
\end{tabular}

PHC primary health care

${ }^{a}$ Confidence interval (81.4-88.6)

${ }^{\mathrm{b}}$ Confidence interval (61.6-71.1)

contraceptive methods among some women. Favoring natural contraceptive methods (36.3\%), the desire of more children (19.0\%), being afraid of health side effects and complications (15.3\%). Other mentioned causes were being afraid of difficulty of getting pregnant (6.5\%), the misconception that modern contraceptives may cause infertility (6.5\%), and the other miscellaneous causes/non-response (16.4\%).

\section{Discussion}

A fundamental change has occurred in Saudi society over the last decades. Socioeconomic development, urbanization, and women's education and work $[7,8,10]$ led to changes in fertility beliefs and behaviors. Results of the present study shed light on an urban community in the north of Saudi Arabia, exploring views, attitudes, and practices of women in the childbearing period regarding family planning, fertility preferences, and health-seeking behavior.

In this study, most of the participating women $(85.3 \%)$ ever used, and $66.5 \%$ were currently using any family planning method/s, which is by far higher than the national estimate for Saudi Arabia (18.6\%) stated in the United Nations (UN) "World Fertility and Family Planning 2020" report and also higher than the international prevalence average, where, in $2019,49 \%$ of all women in the reproductive age range 15-49 years were using some form of contraception [11]. Similarly, the prevalence was also higher than the reported figures in surrounding Gulf Arab countries such as the United Arab Emirates (33.4\%), Kuwait (35.5\%), Bahrain (32.2\%), Oman (19.6\%), Qatar (29.1\%), and other Arab countries such as Egypt (43.2\%), Jordan (31.1\%), Iraq (35.1\%), Syria (31.6\%), Tunisia (34.3\%), and Morocco (36.7\%) [11]. However, the estimate is fairly similar to rates in Western countries such as the UK (71.7\%), France (63.4\%), Italy (55.6\%), Spain (56.5\%), and the USA (61.4\%) [11].

This reported higher rate of family planning methods used in our study population actually concealing a high proportion of couples using traditional unreliable methods, where one in 4 was using these methods compared to $<10 \%$ internationally [11].

Almost all (96.0\%) of the participants in our study praised the concept of family planning and agreed about the benefits of family planning for maternal and child health and well-being. Furthermore, the majority of the participants $(85.3 \%)$ were ever used or currently using (66.5\%) family planning methods. This finding indicates the high acceptability of the family planning concept and points to the real desire of families to plan for the timing of pregnancy occurrence and space between children. Translation of this high acceptance and the higher prevalence of using contraceptives was not reflected in lower fertility profile or smaller family size in our sample. About one-third (32.5\%) were already having more than 3 living children, and 83.0\% reported that they still want more children, and half of them (49.2\%) reported 


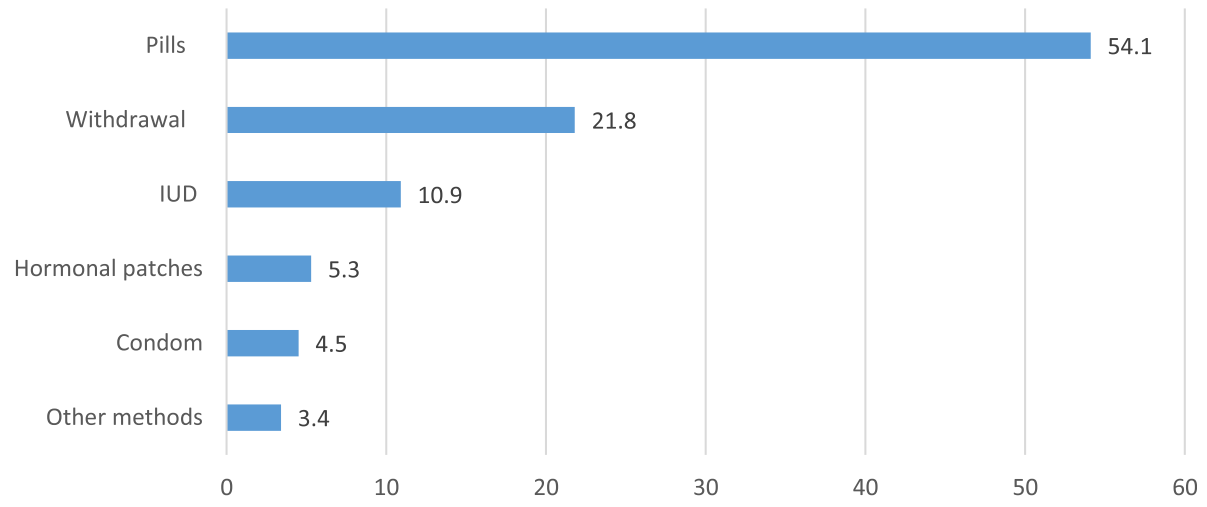

Fig. 2 Contraceptive method currently used among participants (\%)

that they prefer to have more than 3 children. This indicates that the main purpose of using contraceptive methods among the majority of the participants is birth spacing rather than birth limitation. This finding is consistent with previous study conducted in southwestern Saudi Arabia, where $60.0 \%$ of contraceptive users were spacer [12]. This could be explained on the background of cultural factors, religious traditions and customs of an Islamic society as well as personal views.

An important finding in our study is that, the use of contraceptive methods among participants largely depends upon their personal views $(55.0 \%)$ or family/ friends' experience $(23.2 \%)$, while only $21.8 \%$ of the participants received medical advice before using their current contraceptive method. This might explain the higher number of couples who relied on unreliable contraceptive methods and the considerable percentage $(40 \%)$ of the participants who reported that their last pregnancy was unplanned for, which might be attributed to failure of the contraceptive method used. This is not surprising when we find that all participants reported unavailability of a family planning clinic in their PHC centers, with only one in three $(33.8 \%)$ who reported that their PHC centers may provide family planning counseling and just $2.8 \%$ who reported accessibility for prescribing family planning methods. This situation indicates

Table 4 Respondents' views about hesitancy of some women for using modern contraceptive methods for family planning

\begin{tabular}{lll}
\hline Causes & $\boldsymbol{n}$ & $\%$ \\
\hline Natural contraceptive methods are safer & 145 & 36.3 \\
Want more children & 76 & 19.0 \\
Afraid from health side effects and complications & 61 & 15.3 \\
Difficultly of getting pregnant & 26 & 6.5 \\
Cause infertility & 26 & 6.5 \\
Other causes/no response & 66 & 16.4 \\
\hline
\end{tabular}

that, in spite of the high social necessity for family planning revealed by the high demand on family planning methods, there is no parallel availability of organized health services coping for this unmet need of women in the region. As a consequence, healthseeking behavior is self-guided based on personal information and beliefs and/or unreliable sources such as experience of relatives and friends. This crucial need for family planning services was also reported in other studies in Saudi Arabia [12]. The availability of family planning services allows couples to meet their desired birth spacing and family size and contributes to improved health outcomes for children, women, and families [13-15].

Two important consequences might result from choosing a family planning method without medical advice; first, the likelihood of occurrence of avoidable side effects and complications which might affect the users' beliefs and behavior; second, due to resorting to traditional methods of family planning, high rates of contraceptive failure occurs. Dissemination of information about options for contraception should become a part of the routine counseling in primary health care centers and other health care institutions as any decision about contraceptive use should be based not only on contraceptive risks/benefits, but also on the efficacy of the method, individual's life situation, and the level of risk particular to the user characteristics and the life consequences of childbearing for the mother and child [16, 17].

\section{Limitation}

Our study has a number of inherent limitations. Firstly, it is a cross-sectional study, so relationships between the predictor variables and the dependent variables can only be described as general associations not a causal relationship. Second, as an interview survey, social desirability bias cannot be eliminated, and recall bias for some events might happen. Third, our 
study participants were completely from the urban population, so the result cannot be extended to the rural population in the region. However, the current study provides insights to policymakers and health care providers about awareness, attitude, and barriers affecting family planning practice among women in the region to offer need-based health services and to guide health awareness efforts.

\section{Conclusion}

This study revealed that most women in the urban Hail community, northern Saudi Arabia, were aware about and have a positive attitude towards family planning. The majority of women ever used, and two-thirds of them were currently using any family planning method/ s, which is higher than the national estimate for Saudi Arabia. However, only one in five who received counseling for the type of contraceptive method used from healthcare providers. The unavailability of family planning services in primary health care centers impedes getting professional counseling. It is imperious to consider family planning clinics to provide quality family planning services.

\section{Abbreviation}

PHC: Primary health care

\section{Acknowledgements}

We thank directors and healthcare staff in maternity hospital and participated PHC centers, Hail City, Saudi Arabia, for facilitating the study. We also thank the participant mothers for their agreement, patience, and allowing the time to carry out the interview.

\section{Authors' contributions}

GA conceived the study idea, participated in development of the data collection tool, carried out all interviews, and participated in interpretation of the study results. $\mathrm{HH}$ adapted the study idea, designed the data collection tool, carried out data analysis and interpretation of results, and wrote the manuscript. All authors have read and approved the manuscript

\section{Authors' information}

GA: family medicine senior resident, Family \& Community Medicine Joint Program, Hail, Saudi Arabia. HH: Consultant Public Health Medicine; the Designated Institutional Official (DIO) of Academic Affairs \& Postgraduate Studies, Health Affairs, Najran; ex Head of the Research Department, Health Affairs, Hail Region, Saudi Arabia.

\section{Funding}

No funding was received.

\section{Availability of data and materials}

Available from the corresponding author on reasonable request.

\section{Declarations}

\section{Ethics approval and consent to participate}

The protocol of the study was reviewed and approved by the Regional Bioethics Committee of the General Directorate of Health Affairs, Hail region, with the approval number 2019/22 dated October 6, 2019. Agreed participants signed the study consent form. Participants were guaranteed anonymity, confidentiality of the responses, and voluntary participation, and they can withdraw for any reason and any time, without any implications.
Consent for publication

Not applicable.

\section{Competing interests}

The authors declare that they have no competing interests.

\section{Author details}

${ }^{1}$ Family \& Community Medicine Joint Program, Hail, Saudi Arabia. ${ }^{2}$ Academic Affairs \& Postgraduate Studies, General Directorate of Health Affairs, Najran, Saudi Arabia.

Received: 28 October 2020 Accepted: 22 March 2021 Published online: 01 April 2021

\section{References}

1. Cleland J, Bernstein S, Ezeh A, Faundes A, Glasier A, Innis J (2006) Family planning: the unfinished agenda. Lancet 368(9549):1810-1827. https://doi. org/10.1016/S0140-6736(06)69480-4 PMID: 17113431

2. World Health Organization Regional Office for Europe (2000) Definitions and indicators in Family Planning Maternal \& Child Health and Reproductive Health used in the WHO Regional Office for Europe. [Cited 2020 August 3]; Available from: https://apps.who.int/iris/handle/10665/108284.

3. Kantorová V, Wheldon MC, Ueffing P, Dasgupta ANZ (2020) Estimating progress towards meeting women's contraceptive needs in 185 countries: a Bayesian hierarchical modelling study. PLoS Med 17(2):e1003026. https://doi. org/10.1371/journal.pmed.1003026

4. World Health Organization. Family planning/contraception methods fact sheet (2020). Updated 22 June 2020. [cited 2020 Aug. 6]; Available from: https://www.who.int/news-room/fact-sheets/detail/family-planning-contra ception.

5. Family Planning Rights and Empowerment Working Group (2014) Family planning 2020: rights and empowerment principles for family planning. [cited 2020 Aug. 23]. Available from: http://ec2-54-210-230-186.compute-1.a mazonaws.com/wp-content/uploads/2014/12/FP2020_Statement_of_ Principles_FINAL.pdf.

6. United Nations (2019) World population prospects 2019. [cited 2020 Aug. 13]; Available from: https://population.un.org/wpp/Graphs/Probabilistic/ FERT/TOT/682

7. World Health Organization, Regional Office for the Eastern Mediterranean (2013) Country cooperation strategy for WHO and Saudi Arabia 2012 - 2016. [Cited 2020 Aug. 19]; Available from: http://applications.emro.who.int/docs/ CCS_Saudia_2013_EN_14914.pdf.

8. The World Bank (2020) Labor force, female (\% of total labor force) | Data [Internet]. [cited 2020 June 21]. Available from: https://data.worldbank.org/ indicator/SL.TLF.TOTL.FE.ZS

9. Cochran, W. G. (1963) Sampling techniques, 2. Aufl. John Wiley and Sons, New York, London. Preis s. https://doi.org/10.1002/bimj.19650070312.

10. al-Nahedh NN (1999) The effect of sociodemographic variables on childspacing in rural Saudi Arabia. East Mediterr Health J. 5(1):136-140 PMID: 10793791

11. United Nations, Department of Economic and Social Affairs, Population Division (2020) World fertility and family planning 2020: highlights. [Cited 2020 June 27]. Available from: https://www.un.org/en/development/desa/ population/publications/pdf/family/World_Fertility_and_Family_Planning_2 020_Highlights.pdf.

12. Alsaleem MA, Khalil SN, Siddiqui AF, Alzahrani MM, Alsaleem SA (2018) Contraceptive use as limiters and spacers among women of reproductive age in southwestern, Saudi Arabia. Saudi Med J 39(11):1109-1115. https:// doi.org/10.15537/smj.2018.11.22817 PMID: 30397710: PMCID: PMC6274655

13. Centers for Disease Control and Prevention (1999) Achievements in public health, 1900-1999: family planning. MMWR Weekly 48(47):1073-1080 [cited 2020 June 18]. Available from: https://www.cdc.gov/mmwr/preview/ mmwrhtml/mm4847a1.htm

14. Sonfield A, Hasstedt K, Gold RB (2014) Moving forward: family planning in the era of health reform. Guttmacher Institute, New York [cited 2020 Aug 3]. Available from: https://www.guttmacher.org/sites/default/files/report_pdf/fa mily-planning-and-health-reform.pdf

15. Gipson JD, Koenig MA, Hindin MJ (2008) The effects of unintended pregnancy on infant, child, and parental health: a review of the literature. Stud Fam Plann. 39(1):18-38. https://doi.org/10.1111/j.1728-4465.2008.00148. X PMID: 18540521 
16. National Research Council (US) Committee on Population (1989) Contraception and reproduction: health consequences for women and children in the developing world. National Academies Press (US), Washington (DC) PMID: 25144060

17. World Health Organization Department of Reproductive Health and Research (WHO/RHR) and Johns Hopkins Bloomberg School of Public Health/Center for Communication Programs (CCP), Knowledge for Health Project. Family planning: a global handbook for providers (2018 update). Baltimore and Geneva: CCP and WHO, 2018. [Cited 2020 June 21]. Available from: http://www.who.int/reproductivehealth/publications/fp-global-ha ndbook/en/.

\section{Publisher's Note}

Springer Nature remains neutral with regard to jurisdictional claims in published maps and institutional affiliations.

\section{Submit your manuscript to a SpringerOpen ${ }^{\circ}$ journal and benefit from:}

- Convenient online submission

- Rigorous peer review

- Open access: articles freely available online

- High visibility within the field

- Retaining the copyright to your article

Submit your next manuscript at $\boldsymbol{\nabla}$ springeropen.com 